\title{
Вехи истории науки \\ (к 170-летию открытия ионного обмена и 130-летию электродиализа)
}

\author{
(c) 2020 Шапошник В.А., Елисеева Т.В. \\ ФГБОУ ВО «Воронежский государственный университет», Воронеж
}

Поступила в редакцию 24.02.2020 г.

DOI: $10.17308 /$ sorpchrom.2020.20/2786

История развития двух важных научных направлений, связанных с использованием особых свойств полимерных материалов, обладающих способностью к обмену ионов, высокой электропроводностью в набухшем состоянии и селективностью к ионам определенного знака заряда, стала предметом этой статьи. Юбилейные даты открытий явления ионного обмена и метода электродиализа удивительно сочетаются. В 2020 году исполнилось 170 лет первой публикации по ионному обмену и 130 лет первому патенту по электродиализу. Цель данной работы - сделать акцент на общую, психологическую, социальную обстановку, в которой были совершены ключевые открытия в данных научных направлениях, и показать их успешное развитие. Прошло 170 лет с тех пор, как при исследовании сорбции удобрений почвой, был открыт ионный обмен. Революционным в середине прошлого века был синтез катионообменников и анионообменников с высокой химической устойчивостью и значительной обменной ёмкостью. Они позволили создать ряд технологий разделения смесей электролитов, а также смесей электролитов и неэлектролитов. Особое значение имела ионообменная технология получения ультрачистой воды для прецизионных производств. Дальнейший прогресс ионообменной технологии сдерживает отсутствие эффективных методов регенерации сточных вод, однако существуют и развиваются работы по безреагентной регенерации, по использованию нерегенерируемых сорбентов. Ионообменные материалы в виде мембран - главные компоненты современного электродиализа, а гранульные ионообменники - необходимая составляющая гибридного метода электродеионизации. Метод электродиализа возник 130 лет назад при попытках решить проблему очистки сахарных сиропов от солей магния и кальция. 80 лет назад была предложена выдающаяся идея чередования катионселективных и анионселективных мембран при электродиализе, однако, использовались низкоселективные мембраны. И только после синтеза мембран из синтетических полимерных катионообменников и анионообменников эта идея была реализована при создании технологии деминерализации природных солоноватых вод. В сочетании ионного обмена и электродиализа возник метод электродеионизации, позволивший получать ультрачистую воду с безреагентной регенерацией ионообменников и, соответственно, высокими экологическими показателями.

Ключевые слова: ионный обмен, электродиализ, ультрачистая вода, электродеионизация, экология

\section{Введение}

Человек всегда мыслил квантовыми понятиями возможно потому, что учился считать по пальцам и радовался тому, что мог довести счет до пяти пальцев на руке. С тех пор даты, которые можно было разделить на 5, стали поводом для юбилеев. В этом году счастливо сочетаются 170 -летие первой публикации по ионному обмену и 130-летие первого патента по электродиализу. Подробная история ионного обмена изложена в монографиях и статьях [1,2], детальная история электродиализа в статьях[3,4]. Какую цель преследует данная публикация? К. Поппер писал, что только 
человек, понимающий науку, может понять её историю и только человек, понимающий её историю, может понять науку [5]. Цель данной публикации - сделать акцент на общую, психологическую, социальную обстановку, в которой были совершены ключевые открытия в данных научных направлениях, и показать их развитие. Мы надеемся, что многие детали этих открытий могут быть полезны для будущих исследований.

С чего начинается наука или новое научное направление? Принято считать первой страницей, открывающей новую науку или новое научное направление, первую публикацию результатов исследования. Однако ей всегда предшествуют предварительные исследования. Новые явления и закономерности не появляются подобно Афине-Палладе из головы Зевса в блестящих доспехах и с оружием. Они являются результатом наблюдений, обобщения их результатов, мучительного поиска новых идей, дискуссий и синтеза разных интерпретаций. История развития научных представлений о ионном обмене и электродиализе является характерным примером в такой же степени индивидуальным, раскрывающим сложные пути развития научных идей, как и общим.

\section{История ионного обмена}

На первый взгляд может показаться, что ионный обмен - частное явление, а ионообменники являются частным случаем полимеров. Однако анализ истории их развития показывает, что они охватывают круг, включающий почвы, горные породы, синтетические ионообменники в форме гранул, мембран и волокон. Гельферих (в немецком и английском издании) [5], Риман и Уолтон [6,7] начинают историю ионного обмена с библейского чуда пустыни Мерра: «Пришли в Мерру и не могли пить воды в Мерре, ибо она была горька. И возроптал народ на Моисея, говоря: что нам пить? Моисей возопил к Господу, и господь указал ему дерево, и он бросил его в воду, и вода стала сладкой (питьевой) [8]. Риман и Уолтон [7] считали, что древесина, содержащая оксигруппы целлюлозы, которые могут быть окислены до карбоксильных групп, позволяет осуществить реакцию ионного обмена

$$
\mathrm{Mg}^{2+}+\mathrm{SO}_{4}^{2-}+2 \mathrm{RCOOH} \rightarrow(\mathrm{RCOO})_{2} \mathrm{Mg}+\mathrm{H}^{+}+\mathrm{HSO}_{4}^{-}
$$

После этой реакции следовала реакция нейтрализации получающейся серной кислоты известняком. Этот мифологический сюжет является одновременно правдой и неправдой, поскольку такое явление действительно происходит, но в другом масштабе пространства и времени.

Реальная история ионного обмена начинается с 1845 г., когда землевладелец из Керби Томпсон, удостоенный позднее за успехи в сельском хозяйстве титула баронета, решил исследовать сорбцию удобрений почвами. Незадолго до этого в 1840 г. Ю. Либих предложил теорию минерального питания растений и способствовал началу производства минеральных удобрений. Его работы можно сравнить с открытием сразу нескольких континентов, поскольку они привели к существенному изменению жизни человечества и многократному приросту народонаселения земного шара. Видя трудности Томпсона, его друг - химик, фармацевт и владелец Йоркского стекольного завода Спенс изготовил стеклянную колонку и провел предложенный Томпсоном эксперимент. Спенс заполнил колонку смесью торфа и сульфата аммония, который использовался в качестве удобрения. Вопреки ожиданиям, он обнаружил, что только аммоний поглощается торфом, а сульфат в виде кальциевой соли вытекает из колонки. Спенс сообщил результаты Томпсону, но они оба не смогли их интерпретировать и в 1848 г. обратились за помощью к профессору Королевского сельскохозяйственного колледжа Уэю. Уэй сразу оценил значимость проблемы, провел эксперименты и объяснил явление катионного обмена в терминах того времени. Первыми публикациями 
по ионному обмену стали статьи Томпсона и Уэя в одном и том же номере журнала Королевского сельскохозяйственного общества Англии $[9,10]$. Открытие состоялось, но дискуссии о приоритете продолжаются до сих пор. Уэй считал автором открытия Спенса. Многие ученые считают автором открытия Уэя, объяснившего явление, но на международном конгрессе по ионному обмену в Кембридже обратили внимание на то, что именно Томпсон создал проблемную ситуацию, которая привела к открытию. Как говорил выдающийся английский физик и историк науки Д. Бернал: «Гораздо труднее увидеть проблему, чем найти её решение». Вскоре обнаружилось, что большинство горных пород и минералов являются ионообменниками, и можно без преувеличения сказать, что вся поверхность Земли покрыта ионообменниками.

Начальный период деятельности человека в любой сфере связан с изучением и применением природных материалов. Однако, как сказал Леонардо да Винчи: «Там, где природа перестаёт творить собственные объекты, за дело берётся человек». История создания синтетических ионообменников подтверждает слова П.Л. Капицы о том, что науку делают только весёлые люди. Английские исследователи Адамс и Холмс в паузах между измерениями обменной ёмкости природных ионообменников слушали музыку. Однажды они случайно разбили граммофонную пластинку и решили измерить её обменную ёмкость. Пластинка была изготовлена из фенолформальдегидной смолы и имела высокую обменную ёмкость. Адамс и Холмс оформили патент в 1935 г. на изготовление слабокислотных катионообменников [11]. На прогресс в синтезе ионообменников существенное влияние оказали работы Г. Штаудингера, который в 1935 г. синтезировал сшитый полистирол и положил начало научным основаниям химии полимеров. За эти работы в 1953 г. ему была присуждена Нобелевская премия по химии. Сульфированием полистирола в 1945 г. Д’Алелио получил сильнокислотный сульфокатионообменник [12], а Мак Барни в 1952 г. аминированием полистирола синтезировал высокоосновный анионообменник [13]. Схема синтеза сильнокислотного катионообменника на основе стирола и дивинилбензола показана на рис.1.

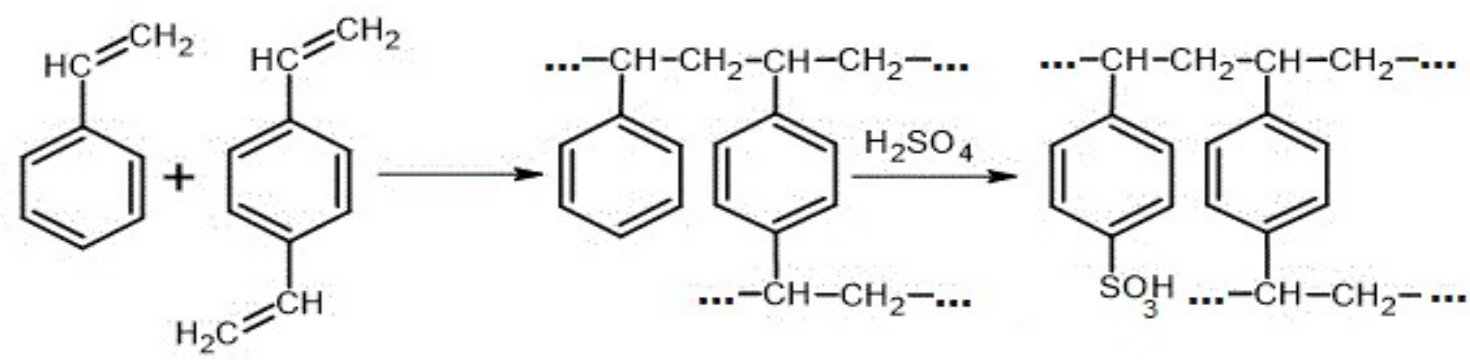

Рис. 1. Схема синтеза сильнокислотного полистирольного сульфокатионообменника

После этих работ применение ионообменников приобрело современные черты. Введение ионогенных групп в полистирол принципиально изменило научные представления о ионном обмене как научной дисциплине, так как наряду с прочными ковалентными связями, характерными для синтетических полимеров, в ионообменниках появились ионные связи, в значительной мере ослабленные гидратацией ионогенных групп и увеличением межионного расстояния. Кроме того, гидратные молекулы у противоионов и фиксированных ионов образовывали слабые водородные связи, что обеспечило ионному обмену высокие скорости протекания реакций. В ионообменниках кроме жестких химических связей, традиционных для полимерных материалов, имеются слабые водородные и ионные связи, что делает их супрамолекулярными со-

Шапошник и др. / Сорбционные и хроматографические процессы. 2020. Т. 20. № 2. С. 305-314 
единениями, которые сочетают сильные связи, обеспечивающие устойчивость структур, и слабые связи, придающие им мобильность и способность к участию в динамических процессах.

Метод ионного обмена был успешно реализован в технологии. Получила распространение ионообменная технология концентрирования радиоактивных изотопов, разделения редкоземельных элементов, разделения аминокислот, извлечения хрома из стоков гальванического производства, меди из производства вискозы и очистки сахара. Очень важным стало применение ионообменной технологии для получения особо чистой воды для прецизионных производств, особенно в микроэлектронике. Технология производства интегральных схем включает десятки методов их химической обработки, после которых требуется промывка глубоко обессоленной водой с удельным электрическим сопротивлением 18.3 МОм см $\left(25^{\circ} \mathrm{C}\right)$. Не является случайностью, что одновременно в 1951 г. были получены качественные транзисторы и предельно чистая вода при применении смешанного слоя катионообменников и анионообменников $[14,15]$.

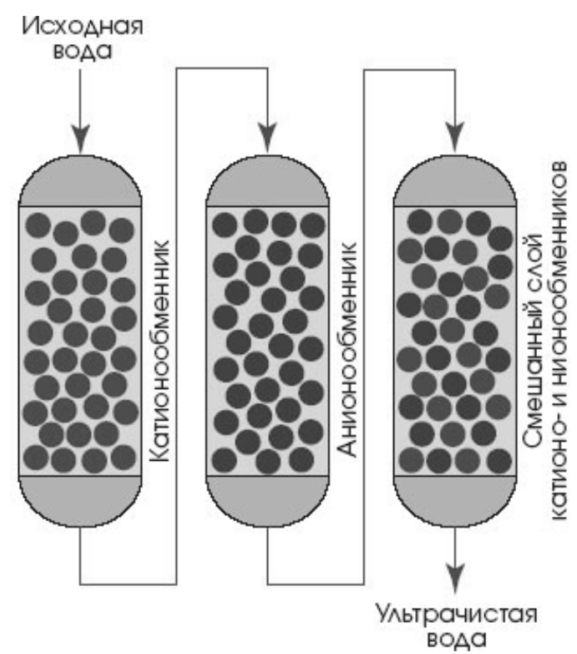

Рис. 2. Схема получения ультрачистой воды методом ионообменной технологии

Особую роль играет ионный обмен в аналитической химии [16]. Была создана ионообменная хроматография, позволяющая эффективно разделять смеси ионов. В этой области особенно очевиден прогресс. Если классическая ионообменная хроматография позволяла определять катионы щелочных металлов за 2-3 суток, то её высокоэффективный вариант, который был назван ионной хроматографией, позволил проводить анализ тех же смесей за 10-20 минут [17]. Информативность анализа увеличилась в тысячи раз [18]. Новизна ионной хроматографии заключалась в том, что для увеличения массоотдачи от гранулы в раствор была применена тонкая плёнка ионообменника, покрывающая нейтральный полимер.

Ионный обмен прошел максимум публикационной активности. Экспоненциальный рост сменился логистической зависимостью числа публикаций во времени. Во многом это следствие успешной работы в более ранний период, когда развивались теоретические методы моделирования кинетики и динамики ионного обмена и сопряженная с ними ионообменная технология. Однако до сих пор в ионном обмене остаётся проблемным экологический аспект, связанный с умножением массы веществ в сточных водах по сравнению с их массой в обрабатываемых растворах (экологический бумеранг) [19]. Внимание исследователей в настоящее время сосредоточено на экологических проблемах технологии. 


\section{История электродиализа}

Электродиализ является методом, объединяющим электролиз и диализ. Открытие электролиза представляется одной из самых интересных страниц истории науки. В 1800 г. А. Вольта усовершенствовал созданный им же гальванический элемент многократным повторением пластинок цинка и серебра. Он описал конструкцию аппарата в письме президенту Лондонского королевского общества Д. Бенксу 20 марта 1800 г. Письмо заинтересовало члена общества известного хирурга профессора А. Карлайла. Он отменил лекции, операции и изготовил из серебряных полукрон и цинковых кружков гальванический элемент. Для анализа газов, выделявшихся на электродах, помещенных в воду, он привлек химика, физика и издателя У. Николсона, который определил, что при пропускании электрического тока на электродах выделялись кислород и водород. А. Карлайл, удовлетворив свою любознательность, не придал опыту особого значения в отличие от У. Николсона, который написал статью [20]. Так был открыт электролиз. Позже, когда Г. Дэви открыл с использованием электролиза натрий, калий, бор, кальций, барий и кадмий, А. Карлайл пожалел, что не мог оценить по достоинству собственное открытие. Диализ был открыт в 1827 г. Р. Дютроше [21]. Особый интерес представляют работы Т. Грэма, который использовал диализ для разделения истинных и коллоидных растворов. Эти работы легли в основу созданной им коллоидной химии [22].

Первую работу по электродиализу выполнили кубинцы У. Майгрот и Х. Сабатес, решая практическую задачу деминерализации сахарного сиропа. В 1890 г. они получили патент Германии на предложенный ими метод [23]. Рис. 3, представляющий схему первого электродиализатора, позволяет сравнить достижения науки за 130 лет.

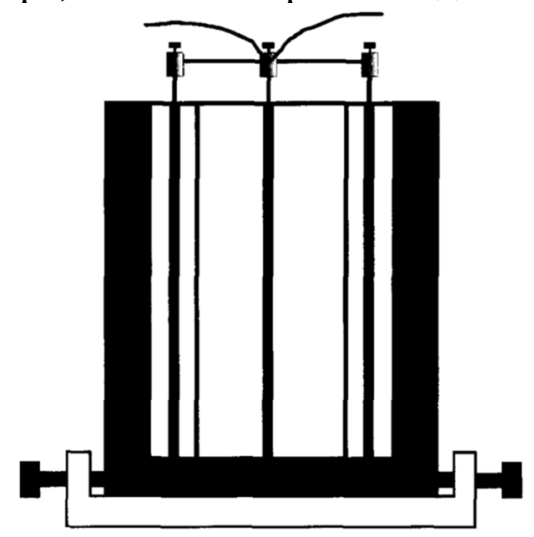

Рис. 3. Схема первого электродиализатора [23]

Корпус аппарата был изготовлен из дерева, электроды из угля, мембраны из пергаментной бумаги, а электрический ток подавали от динамомашины. Соли кальция и магния мигрировали к катоду через мембрану, очищая сахарный сироп. В этом патенте термин электродиализ не использовался. Он появился впервые в 1900 г. в патенте Г. Шоллмайера [24]. В первых работах не только применялись мембраны с низкой селективностью, но и не было сформировано понятие о селективности мембран для ионов разного знака заряда. В историю науки И.В. Гитторф вошел как ученый, который ввел в физическую химию представления о числах переноса и как создатель первой электронной трубки. Будучи на пенсии, он следил за экспериментальными работами по измерению чисел переноса, которые существенно различались у разных авторов. Гитторф пришел к выводу, что причиной различия являются изменения чисел переноса мембран, разделяющих катодную и анодную секцию [25]. Биологи Лёб и Бойтнер в 1912 г. обнаружили избирательную проницаемость яблочных шкурок для 
катионов [26]. Вскоре выяснилось, что большинство природных мембран, в том числе природных модифицированных, как, например, известные мембраны из коллодия, были селективно проницаемы для катионов. Впервые сорбцией белков Л. Михаэлис получил коллодиевые мембраны, избирательно проницаемые для анионов [27].

Имея катионоселективные и анионоселективные мембраны, К. Майер и В. Штраус в лаборатории неорганической и органической химии Женевского университета в 1940 г. (ровно 80 лет и еще один юбилей) предложили принцип чередования их в многосекционном электродиализаторе (рис.4) [28].

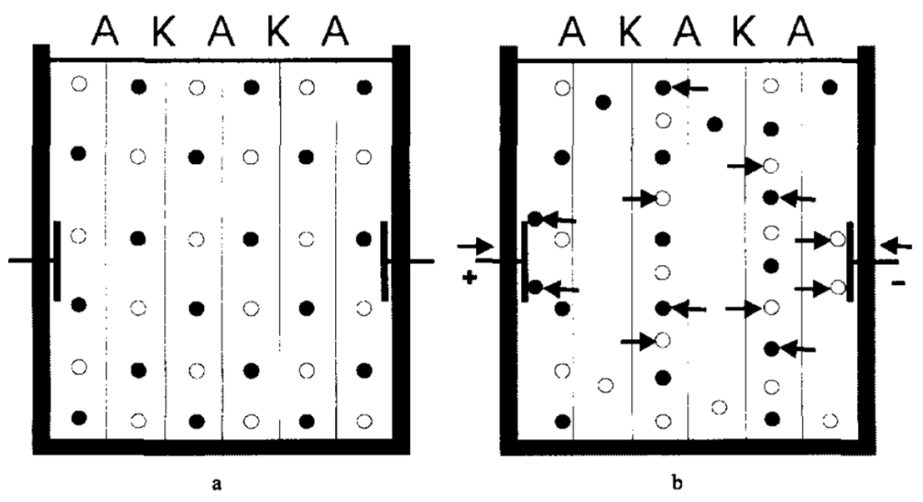

Рис. 4. Схема электродиализатора с чередующимися катионоселективными $($ К) и анионоселективными мембранами $(\mathrm{A})$. Распределение катионов $(\bullet)$ и анионов(о) в растворах секций. $\mathrm{a}-$ до, $\mathrm{b}$ - после пропускания электрического тока [28]

Рис. 4, взятый из их работы [28], демонстрирует принцип деионизации и концентрирования, положенный в основу функционирования большинства современных электродиализаторов. При протекании постоянного тока равномерное распределение концентраций сменяется накоплением электролита в секциях концентрирования и уменьшением концентрации в смежных с ними секциях обессоливания.

После того как Крессманом, Джуда и Мак Реем в 1950 г. (70 лет и ещё одна юбилейная дата) были получены мембраны из катионообменников и анионообменников с селективностью, близкой к идеальной, определилось основное направление приложения электродиализа - деминерализация природных вод [29]. В 1959 г. в штате Гедулд (ЮАР) была пущена в эксплуатацию установка, позволяющая получить из солоноватых шахтных вод пресную для водоснабжения шахтерского городка. Эксперты разных стран оценили решение проблемы деминерализации солоноватых природных вод не только как техническое, но и как социально-политическое достижение, особенно важное для полуаридных регионов. Конкуренцию электродиализу составил другой мембранный метод обратного осмоса. В первый период граница между ними проходила по концентрации 8 г/дм³. Обратный осмос был признан эффективным при больших концентрациях, а электродиализ при меньших. Подземные солоноватые и шахтные воды попадали в сферу эффективного электродиализа. В настоящее время успехи обратного осмоса сдвинули границу эффективности этого мембранного метода к меньшим значениям солесодержания природных и сточных вод. Подвижная граница между электродиализом и обратным осмосом будет определяться новыми достижениями в развитии этих методов.

Однако электродиализ получил новый импульс. Уотерс, Вейзер и Марек для концентрирования радиоактивных изотопов применили электродиализ с межмембранной засыпкой секций аппарата смешанным слоем катионообменников и анионообменников [30], который получил позже название непрерывной электродеионизации 
(CEDI). Работы по получению чистой воды начал Глюкауф [31], который не смог достичь «полюса» чистоты. Следующий шаг был сделан Н.П. Гнусиным и В.Д. Гребенюком, которые установили, что при электродеионизации разбавленных растворов необходимо для увеличения эффективности процесса не увеличивать, а уменьшать плотность постоянного электрического тока [32, стр. 165]. Неудачный выбор геометрических параметров аппарата не позволил им создать непрерывно работающую установку получения ультрачистой воды, и они предложили теорию «выброса электролитов» согласно которой цепь гранул разной полярности, ориентированная подобно мембранам в секции обессоливания при высокой степени деионизации, выключалась из цепи вследствие высокого электрического сопротивления. Напротив, гетерополярные контакты гранул, ориентированных подобно мембранам в секциях концентрирования, активно функционировали, что приводило к концентрированию, а не обессоливанию растворов [32, стр. 148]. Авторы этой монографии не обратили внимание на роль необратимой диссоциации воды на контактах мембран, которая не приводит к отключению части контактов на границе гетерополярных гранул, и тем более не обратили внимание на определяющую роль эквиполярных контактов гранул при глубокой деионизации растворов. В работе [33] был предложен метод непрерывного получения ультрачистой воды, который был отмечен уже в публикации [34]. В обзоре работ по непрерывной электродеионизации 1998 г. [35] первой работой по электродеионизации с целью получения ультрачистой воды была названа работа Матейки 1971 г. [36], а работа [33], опубликованная в 1973 г., следовала за ней. Однако Матейка получил воду с удельным электросопротивлением 10 МОм см [36], что вдвое меньше предельного и недостаточно для использования в финишных установках предприятий микроэлектроники. В работе [33] было достигнуто предельное удельное сопротивление, необходимое для использования в прецизионных производствах. Обзор фундаментальных проблем электродиализа и его практических применений содержится в монографиях [37,38].

\section{Заключение}

Как поживают сегодня 170 -летний ионный обмен и 130 -летний электродиализ? Они добились успехов как в развитии теории конденсированного состояния, так и на практике для создания технологий глубокой очистки веществ. Оба научных направления могли бы стать самостоятельными науками, но не стали. Одной из причин является отсутствие удачных названий этих направлений, отражающих их новизну, важное значение и содержание. А. Пуанкаре писал, что трудно поверить, какую огромную экономию мысли может осуществить одно хорошо подобранное слово, и это слово становится творцом. Таких слов для ионного обмена и мембранной электрохимии не нашлось. Предложенные нами в докторской диссертации термины мембраника, а для мембранной электрохимии электромембраника не прижились. Ещё сложнее дать значимое название направлению исследований в области ионного обмена. Термин ионика уже занят электрохимией электролитов, а термин ионообменника кажется слишком прямолинейным. Для более частных методов ионной хроматографии и электродеионизации были предложены более удачные термины. История развития научных направлений ионного обмена и электродиализа свидетельствует об их реальных достижениях и вселяет надежду на успешное будущее.

\section{Список литературы}

1. Сенченкова Е.М. Рождение идеи и метода адсорбционной хроматографии. М. Наука. 1992. 228 с.
2. Иванов В.А., Горшков В.И. // Сорбичионные и хроматографические прочессы. 2006. T.6. № 1. C. 5-31. 
3. Shaposhnik V.A., Kesore K. // J. Membrane Sci. 1997. Vol. 136. pp. 35-39.

4. Шапошник В.А. // Мембраны. 2000. № 8. C. 49-54; 2001. № 10. C. 9-17.

5. Поппер К. Объективное знание. М. УPPC. 2002. $384 \mathrm{c}$.

6. Гельферих Ф. Иониты. М. ИЛ. 1962. 489 c.

7. Риман В., Уолтон Г. Ионообменная хроматография. М. Мир. 1973.375 с.

8. Библия. Исход. 15, 22-25.

9. Thompson H.S. // Roy. Agr.Soc.Engl. 1850. Vol. 11. pp. 68-74.

10.Way J.T. // Roy. Agr.Soc. Engl. 1850. Vol. 11. pp. 313-380.

11.Adams B.A., Holmes E.L. Brit. Pat. No 450308. 1935.

12.D’Alelio G.F. U.S. Pat. No 2366007. 1945.

13.McBurney C.H. U.S. Pat. No 25911573. 1952.

14.Reents A.C., Kahler P.H. // Ind. Eng. Chem. 1951. Vol. 43. pp. 730-734.

15.Kunin R., McGarvy F. // Ind. Eng. Chem. 1951. Vol. 43. pp. 734-740.

16.Самуэльсон О. Ионообменные разделения в аналитической химии. М.-Л. Химия. 1966. $416 \mathrm{c}$.

17.Small H., Stevens T.S., Bauman W.S. // Anal. Chem. 1975. Vol. 47. No 11. pp. 18011809.

18.Шапошник В.А. // Сорбиионные и хроматографические проиессы. 2018. Т. 18. № 2. С. 131-135.

19.Шапошник В.А., Мазо А.А., Фрёлих П. // Успехи химии.1991. Т. 60. № 11. С. 2469-2483.

20.Nicholson W., Carlisle A. // Phil. Mag. 1800. Vol. 4. pp. 179-187.

21.Dutrochet R.J.H. // Annales Chem.et Phys. 1827. Vol. 35. pp. 393-400
22.Graham T. // Phil. Trans. Roy. Soc. London.

1861. Vol. 151. pp. 183-224.

23.Maigrot E., Sabates J. Germ. Pat. No 50443 (1890).

24. Schollmeyer G. Germ. Pat. No 109589 (1900)

25.Hittorf W. // Z. phys. Chem. 1902. Bd. 39. pp. 613-630.

26.Loeb J., Beutner R. // Science. 1912. Vol. 35. No 913. pp. 970-971.

27.Michaelis L. // J. Gen. Physiol. 1925. Vol. 8. pp. 33-59.

28. Meyer K.H., Straus W. // Helv. Chem. Acta. 1940. Vol. 23. pp. 795-800.

29. Деминерализация методом электродиализа. М. Госатомиздат.1953. 351 с.

30.Walters W.R., Weiser D.W., Marek J.I. // Ind. Eng. Chem. 1955. Vol. 47 (1). pp. 61-67.

31.Glueckauf E. // Brit. Chem. Eng. 1959. Vol. 4. pp. 646-651.

32.Гнусин Н.П., Гребенюк В.Д. Электрохимия гранулированных ионитов. Киев. Наукова думка. $1972.180 \mathrm{c.}$

33.Шапошник В.А., Решетникова А.К., Золотарёва Р.И., Дробышева И.В. и др. // Журн. прикл. химии. 1973. Т. 46. № 12. С. 2659-2663.

34.Govindan K.P., Narayanan P.K. // Desalination. 1976. Vol. 19. pp. 229-239.

35.Di Mascio F., Wood J., Fenton J.M. // The Electrochem. Soc. Int. 1998. pp. 26-29.

36. Matejka Z.// J. Appl. Chem. Biotechn. 1971. Vol. 21. pp. 117-120.

37. Tanaka Y. Ion Membranes: Fundamentals and Application. Amsterdam. Elsevier. 2007. $532 \mathrm{p}$.

38.Заболоцкий В.И., Никоненко В.В. Перенос ионов в мембранах. М. Наука. 1996. 392 c.

\title{
Milestones in the history of science (for the 170th anniversary of ion exchange discovery and the 130th anniversary of electrodialysis)
}

\author{
(C) 2020 Shaposhnik V.A., Eliseeva T.V. \\ Voronezh State University, Voronezh
}

\begin{abstract}
The subject studied in this article is the history of the development of two important scientific fields related to the use of special properties of polymer materials that are capable of ion exchange and are characterised by high electrical conductivity in swollen state and selectivity in relation to ions with a certain charge. The anniversaries of the discoveries of the ion exchange phenomenon and the method of electrodialysis are surprisingly interconnected. 2020 marks 170 years since the first publication on ion exchange and 130 years since the first patent in the field of electrodialysis. The goal of this work is to put an emphasis on general, psychological, and social atmosphere in which key discoveries were made in the specified scientific fields, and to show their successful development. 170 years have passed since ion exchange was discovered when the
\end{abstract}


sorption of fertiliser by soil was being studied. The synthesis of cation exchange resins and anion exchange resins with high chemical stability and significant exchange capacity was revolutionary in the middle of the last century. They allowed creating a number of technologies for the separation of electrolyte mixtures as well as the mixtures of electrolytes and non-electrolytes. Ion exchange technology for obtaining ultrapure water for precise manufacturing was especially important. Further progress of ion exchange technology is hindered by the absence of effective methods of waste water regeneration. However, there are some developments in the field of reagentless regeneration and the use of non-regenerable sorbents. Ion exchange materials in the form of membranes are the main components of modern electrodialysis while granular ion exchangers are an essential component of the hybrid method of electrodeionization.

The method of electrodialysis emerged 130 years ago while attempting to solve the problem of purification of sugar syrups from magnesium and calcium carbonates. 80 years ago, an outstanding idea to alternate cation-selective membranes with anion-selective membranes during electrodialysis was suggested, although low selective membranes were used. Only after the synthesis of the membranes from synthetic polymer cation exchange resins and anion exchange resins this idea was implemented in the development of technologies for the demineralisation of natural brackish water. The combination of ion exchange and electrodialysis generated a method of electrodeionization that allowed ultrapure water with reagentless regeneration of ion exchangers to be obtained and, correspondingly, with high environmental value.

Keywords: ion exchange, electrodialysis, ultrapure water, electrodeionization, ecology.

\section{References}

1. Senchenkova E.M. The birth of idea and method of adsorption chromatography, M., Nauka, 1991, $228 \mathrm{p}$.

2. Ivanov V.A., Gorshkov V.I., Sorptsionnye $i$ khromatographicheskie protsessy, 2006, Vol. 6, No 1, pp. 5-31.

3. Shaposhnik V.A., Kesore K., J. Membr. Sci., 1997, Vol. 136, pp. 35-39.

4. Shaposhnik V.A., Membranes, 2000, No 8., pp. 49-54; 2001, No 10, pp. 9-17.

5. Popper K. Objective knowledge, Oxford, Clarendon Press, 1972, 384 p.

6. Helfferiich F., Ionenaustauscher. Weinheim.Verlag Chemie, 1959, 489 p.

7. Rieman W., Walton H.F., Ion exchange in analytical Chemistry. Oxford. Pergamon Press, 1970, $375 \mathrm{p}$.

8. Bible. Moses. Exodus. 15. 22-25.

9. Thompson H.S., Roy. Agr. Soc. Engl., 1850, Vol. 11, pp. 68-74.

10.Way J.T., Roy. Agr. Soc. Engl., 1850, Vol. 11, pp. 313-380.

11.Adams B.A., Holmes E.L. Brit. Pat. No 450308, 1935.

12.D'Alelio G.F. U.S. Pat. No 2366007, 1945.

13.McBurney C.H. U.S. Pat. No 25911573, 1952.

14.Reents A.C., Kahler P.H., Ind. Eng. Chem., 1951, Vol. 43, pp. 730-734.

15.Kunin R., McGarvy F., Ind. Eng. Chem., 1951, Vol. 43, pp. 734-740.

16. Samuelson O. Ion exchange separations in analytical chemistry, Stockholm, Almvisf\&Wiksell. $1953,416 \mathrm{p}$.

17.Small H., Stevens T.S., Bauman W.S., Anal. Chem., 1975, Vol. 47, No 11, pp. 1801-1809.
18.Shaposhnik V.A., Sorptsionnye i khromatographicheskie protsessy, 2018, Vol. 18, No 2, pp. 131-135.

19.Shaposhnik V.A., Mazo A.A., Frolich P., Russian. Chem. Reviews, 1991, Vol. 60, No 11, pp. 2469-2483.

20.Nicholson W., Carlisle A., Phil. Mag., 1800, Vol. 4, pp. 179-187.

21.Dutrochet R.J.H., Annales Chem. et Phys., 1827, Vol. 35, pp. 393-400.

22. Graham T., Phil. Trans. Roy. Soc. London, 1861, Vol. 151, pp. 183-224.

23.Maigrot E., Sabates J., Germ. Pat. No 50443 (1890).

24. Schollmeyer G. Germ. Pat. No 109589 (1900).

25.Hittorf W., Z. phys. Chem., 1902, Bd. 39, pp. 613-630.

26.Loeb J., Beutner R., Science, 1912, Vol. 35, No 913, pp. 970-971.

27.Michaelis L., J. Gen. Physiol., 1925, Vol. 8, pp. 33-59.

28.Meyer K.H., Straus W., Helv. Chem. Acta., 1940, Vol. 23, pp.795-800.

29. Demineralization by electrodialysis. London. Butterworths Sc. Pub. 1960. 378 p.

30.Walters W.R., Weiser D.W., Marek J.I., Ind. End. Chem., 1955, Vol. 47 (1), pp. 61-67.

31.Glueckauf E., Brit. Chem. Eng., 1959, Vol. 4, pp. 646-651.

32. Gnusin N.P., Grebenyuk V.D. Electrochemistry of granular ion exchangers, Kyiv, Naukovadumka, 1972, $180 \mathrm{p}$.

33. Shaposhnik V.A., Reshetnokova A.K., Zolotareva R.I., Drobysheva I.V. et al., Zhurnal 
Prikladnoi Khimii, 1973, Vol. 46, No 12, pp. 2659-2663.

34.Govindan K.P., Narayanan P.K., Desalination, 1976, Vol. 19, pp. 229-239.

35.Di Mascio F., Wood J., Fenton J.M., The Electrochem. Soc. Int., 1998, pp. 26-29.

Шапошник Владимир Алексеевич - д.х.н., профессор кафедры аналитической химии Воронежского госуниверситета, Воронеж

Елисеева Татьяна Викторовна - к.Х.н., доцент, зав. кафедрой аналитической химии Воронежского госуниверситета, Воронеж
36.Matejka Z., J. Appl. Chem. Biotechn., 1971, Vol. 21, pp. 117-120.

37. Tanaka Y. Ion Membranes: Fundamentals and Application. Amsterdam, Elsevier, 2007, $532 \mathrm{p}$.

38.Zabolotsky V.I., Nikonenko V.V., Ion transport in membranes, M., Nauka, 1996, 392 p.

Shaposhnik Vladimir A. - Dr. Sc., Professor, Department of Analytical Chemistry Voronezh State University, Voronezh, e-mail: v.a.shaposhnik@gmail.com

Eliseeva Tatiana V. - Ph. D., Ass. Prof., Head of Analytical Chemistry Department, Voronezh State University, Voronezh, e-mail: tatyanaeliseeva@yandex.ru 